\section{Demandas y expectativas de jóvenes residentes en colonias empobrecidas de Centroamérica}

\author{
Carlos Sandoval García1
}

Palabras clave:

Centroamérica, jóvenes, violencia, cultura política, desigualdades, migraciones.

\section{Resumen}

Este artículo analiza demandas y expectativas de jóvenes residentes en colonias empobrecidas de las capitales de Centroamérica a partir de cuatro temas principales: la representación del entorno local y nacional, las demandas y los deseos en torno al futuro, los medios que imaginan para alcanzar o no dichas demandas y factores sociodemográficos. Las colonias seleccionadas fueron El Limón, en Ciudad de Guatemala; Popotlán, en San Salvador; Nueva Capital, en Tegucigalpa; Jorge Dimitrov, en Managua, y La Carpio, en San José. Se parte de tres desafíos teóricos y metodológicos principales. El primero es explorar la vivencia de la política desde la exclusión social. El segundo reto se refiere a trascender la división entre estudios interesados por perspectivas analíticas, más interesados en estudios causales, y aquellos más focalizados en estudios interpretativos, cuya mirada se centra en significados. El tercer reto aspira a contribuir en la construcción de una mirada regional y comparada de las sociedades centroamericanas.

Entre los hallazgos principales, se destaca que un $37.7 \%$ de las personas encuestadas no estudia ni trabaja; solamente un $15 \%$ tiene acceso a la seguridad social. De las personas encuestadas, un $32 \%$ es madre y un $13 \%$ es padre. Un $45 \%$ de las mujeres que son mamás lo fueron antes de los 18 años. En términos de la percepción del entorno, los principales problemas reconocidos son la delincuencia, el desempleo y las

$1 \quad$ Carlos Sandoval García (1964), carlos.sandoval@ucr.ac.cr, es doctor en Estudios Culturales por la Universidad de Birmingham en Inglaterra y profesor de la Universidad de Costa Rica. Coordina el Doctorado en Ciencias Sociales sobre América Central. En la actualidad, se desempeña como vicerrector de Vida Estudiantil. Su próximo libro se titula Centroamérica desgarrada. 
carencias de infraestructura pública. Si bien la desigualdad no se tematiza como uno de los principales problemas, cuando se consulta por la distribución de la riqueza en el país respectivo, un $73.6 \%$ considera que es "muy injusta" o "injusta". Este reconocimiento de la desigualdad coexiste con un arraigado conservadurismo que reconoce en el destino y la autoridad de los padres una legitimidad poco cuestionada.

Este artículo concluye que las principales expectativas y demandas de las personas jóvenes encuestadas se centran especialmente en el empleo, las oportunidades y la seguridad. Frente a estas demandas, el ciclo electoral que inició en Honduras en 2017 y finalizó en Guatemala en 2019 está lejos de ofrecer respuestas de gran calado. Ello profundiza el vacío institucional y a menudo la migración más que una elección se convierte en una obligación.

\section{Abstract}

This article analyzes demands and expectations of young residents of impoverished neighborhoods in Central American capital cities. Four main subject areas are explored: the representation of the local and national environment, demands and desires for the future, the means by which young people expect to achieve (or not achieve) said demands, and sociodemographic factors. The selected neighborhoods were El Limón in Guatemala City, Popotlán in San Salvador, Nueva Capital in Tegucigalpa, Jorge Dimitrov in Managua, and La Carpio in San José. A sample of 300 respondents were selected using sampling quotas.

One of the primary findings of the study is that $37.7 \%$ of participants neither study nor work and that only $15 \%$ have access to social security. Although inequality was not identified as being among the most pressing problems, when asked about the distribution of wealth in their respective countries, $73.6 \%$ of participants considered said distribution to be "very unfair" or "unfair". This recognition of inequality coexists with a deeply rooted conservatism and a largely unquestioned belief in the legitimacy of destiny and parental authority.

The electoral cycle that began in Honduras in 2017 and concluded in Guatemala in 2019 is far from offering any kind of significant or profound response. This electoral cycle has deepened the institutional void, and in many cases immigration has become more of an obligation than a choice.

Keywords: Central America, youth, violence, political culture, inequalities, migration.

\section{Introducción}

Un caluroso domingo de septiembre 2013, tres jóvenes esperaban la salida del tren llamado "La Bestia" en Coatzacoalcos, Veracruz, México. Ellos habían finalizado sus estudios de secundaria y no encontraban empleo remunerado en Honduras. Entonces, decidieron dejar su país e intentar llegar a los Estados Unidos. No conocían la ruta del golfo de México que habían elegido y tampoco tenían parientes en los Estados Unidos que les pudieran enviar dinero para pagar el cruce de la frontera. Uno de ellos tristemente resumió muchos debates: "De por sí, si nos van a matar en Honduras, que nos maten aquí" (Sandoval, 2015, p. 41).

Dos años después, en 2015, Geovanny, un joven salvadoreño había llegado a la ciudad de Saltillo, en el estado de Cohauila, ubicado a unos 500 kilómetros de la frontera entre México y los Estados Unidos. Él tenía la expectativa de cruzar la frontera y encontrar un empleo. Soñaba con comprarle una casa a su abuela, a quien extrañaba mucho, también a su hermano menor. "Ser joven en El Salvador es un delito", concluyó mientras recordaba los motivos que le hicieron dejar su país.

Estos dos encuentros fueron un punto de partida vital para la investigación que sirve de base de este artículo, el cual se propone docu- 
mentar y discutir demandas y expectativas de jóvenes residentes en barriadas empobrecidas de las capitales de Centroamérica. La investigación incluye cuatro temas principales: la representación del entorno local y nacional, las demandas y deseos en torno al futuro, los medios que imaginan para alcanzar o no dichas demandas y factores sociodemográficos. En su conjunto, estos cuatro temas se interrogan sobre los vínculos entre factores materiales, formas de representación de estos y constitución de subjetividades.

Los Acuerdos de Esquipulas II, firmados en el año 1987 por los presidentes de Centroamérica, prometieron la "paz duradera". Estos acuerdos fueron dedicados a las personas jóvenes de la época, tal y como se lee en el documento: "Dedicar a las juventudes de América Central, cuyas legítimas aspiraciones de paz y justicia social, de libertad y reconciliación, han sido frustradas durante muchas generaciones, estos esfuerzos de paz".

La transición política estuvo acompañada por la introducción de políticas neoliberales, las cuales disminuyeron las ya endebles condiciones laborales y la presencia del Estado en la prestación de servicios y en la puesta en práctica de políticas de redistribución de la riqueza en muchas regiones y territorios. Incluso en Costa Rica, donde no se vivió una transición política como la descrita, se ha experimentado un incremento de la desigualdad (Amarante et al., 2016).

El Informe Estado de la Región (2011) estima que Centroamérica cuenta con una población de 43 millones de personas. Para el año 2025, el aumento podría ser de alrededor de once millones. Cerca de dos tercios viven en zonas urbanas y cuatro de diez personas son menores de 18 años. Los procesos de urbanización han sido intensos; entre 1990 y 2010, la población que habita en zonas urbanas se incrementó de un $44.1 \%$ a un 58.5 \% (Informe Estado de la Región, 2011, p. 112). La población joven tiene un peso particularmente significativo en Guatemala, Honduras y Nicaragua; no así en El Salvador,
Costa Rica y Panamá, países que experimentan una transición demográfica caracterizada por un descenso de la tasa de natalidad. Un $37.78 \%$ de la población del istmo subsiste en condiciones de nulo o precario acceso al trabajo, a la seguridad social y mantiene bajísimos niveles de educación formal (p. 459). Este porcentaje se incrementa de manera considerable si se analizan indicadores de regiones costeras o rurales del istmo. En Nicaragua y El Salvador, países caracterizados por una alta exclusión, el sector formal cubre a menos del $40 \%$ de la población económicamente activa (PEA) (p. 474); mientras que, en Costa Rica, el sector formal puede alcanzar un $60 \%$.

Centroamérica no se comprende sin considerar la impronta geopolítica del narcotráfico. Ello ha incrementado las disputas territoriales por el control de la distribución y venta de sustancias ilícitas, la posesión de armas y el incremento de la violencia que a menudo se traduce en pérdida de vidas humanas. Se estima que el índice de homicidios para Centroamérica, por cada 100,000 habitantes, es de 35.4 personas; mientras tanto, para América Latina es de alrededor de 20.

Por su parte, San Pedro Sula, con 111 homicidios por 100,000 habitantes es, después de Caracas, la segunda ciudad más violenta del mundo. El Salvador es el país con la tasa de homicidios más alta, con 103 muertes por 100,000 habitantes. En Honduras, apenas un $3 \%$ de los casos de homicidios terminan con una condena. Estas estimaciones excluyen zonas o ciudades en contextos de guerra (Hansen-Nord et al., 2016).

Junto con la violencia estructural y la violencia criminal, la migración es un tercer rasgo estructural de la región centroamericana. Se estima que, al menos, entre un 12 y un $14 \%$ de la población de Centroamérica ha abandonado sus países de nacimiento. Así pues, Centroamérica cuadruplica la migración internacional estimada a nivel mundial, la cual se calcula en un $3 \%$, y duplica la migración latinoamericana que alcanzaría un $6 \%$, es 
decir, unos 25 millones, 15 de los cuales han emigrado en las dos últimas décadas, cuando los tratados de libre comercio han profundizado las políticas neoliberales en la región (Sandoval, 2015).

Si se comparan los censos de Estados Unidos de los años 2000 y 2010, se estima que la población centroamericana en aquel país aumentó en un $136 \%$. Honduras (191.1 \%), Guatemala (180.3 \%) y El Salvador (151.7 \%) son los países con un mayor crecimiento de la población que vive en Estados Unidos. Incluso un país como Costa Rica, más bien conocido como país receptor, reporta un aumento de un $84.3 \%$ de la población residente en Estados Unidos, entre el 2000 y el 2010 (Sandoval, 2015).

En síntesis, si las transiciones democráticas favorecieron el final de las guerras civiles que fueron especialmente cruentas durante la década de 1980, en vísperas del Bicentenario de la Independencia no se avizoran estrategias de gran aliento para superar estos nuevos escenarios de conflicto. Algunos análisis, aún incipientes, sugieren que este panorama podría caracterizarse como de "guerra social" (Gutiérrez, 2016), por cuanto hay agrupaciones con algún nivel de formalización que se disputan el control de territorios y otros recursos de poder.

\section{Ni la "gran teoría" ni el "empirismo abstracto"}

Este artículo parte de tres desafíos teóricos y metodológicos principales. El primero es explorar la vivencia de la política desde la exclusión social. El auge de perspectivas populistas, por ejemplo, a veces alentadas desde iglesias neopentecostales, desconciertan y a menudo se producen críticas a sus supuestos ideológicos y consecuencias políticas, pero se comprende relativamente poco el porqué de su legitimidad en comunidades empobrecidas. El segundo reto se refiere a trascender la división entre estudios interesados por perspectivas analíticas, más centrados en estudios causales, y aquellos más focalizados en estudios interpretativos, cuya mirada se centra en significados. Los primeros suelen ser cuantitativos y los segundos cualitativos.

El tercer reto aspira a contribuir en la construcción de una mirada regional y comparada de las sociedades centroamericanas. En su conjunto, este proyecto aspira a una ciencia social de a pie, interesada en trascender tanto "la gran teoría" como el "empirismo abstracto", caracterizados respectivamente por el "fetichismo de los conceptos" y la "inhibición metodológica", para decirlo con las palabras de Charles Wright Mills (1987).

En términos metodológicos, Immanuel Wallerstein (1996, p. 103) anota que las ciencias sociales se construyeron sobre varias antinomias. Una de ellas es la separación entre enfoques explicativos (nomotéticos), interesados en análisis causales, y enfoques interpretativos (ideográficos), los cuales priorizan el análisis de significados. La encuesta que está a la base de este artículo procuró a trascender esta antinomia, pues al tiempo que intenta identificar factores causales que podrían contribuir a explicar formas de percibir el entorno, el futuro y los medios para alcanzar o no este último, también se interroga por los significados asociados a estos tres planos de análisis.

En términos metodológicos, dos contribuciones de Pierre Bourdieu (1990) son indispensables. Una se sintetiza en la lacónica frase de que "la juventud no es más que una palabra", según la cual "solo con un abuso tremendo del lenguaje se puede colocar bajo el mismo concepto universos sociales que no tienen nada en común" (p. 165) (véase también Duarte, 1990; Margulis, 1996). La edad y la generación se articulan (Hall, 2010) e interseccionan (YuvalDavis, 2012; Hill Collins y Bilge, 2016) con otras dimensiones de la existencia social como la clase, el género, la sexualidad, la etnicidad, para mencionar algunas, en contextos espacio temporales específicos. 
La segunda contribución es la afirmación de que "la opinión pública no existe". Ello, dice Bourdieu, tiene tres implicaciones:

Cualquier encuesta de opinión supone que todo el mundo puede tener una opinión; o, dicho en otras palabras, que la producción de una opinión está al alcance de todos... se supone que todas las opiniones tienen el mismo valor... en el simple hecho de plantear la misma pregunta a todo el mundo está implicada la hipótesis de que hay un consenso sobre los problemas, en otras palabras, que hay un acuerdo sobre las preguntas que merece la pena hacer (1990, p. 239).

Los trabajos de Norbert Lechner constituyen una mediación indispensable para responder estos retos enunciados por Bourdieu. Si bien corresponde guardar las diferencias entre el contexto de la dictadura de Pinochet, en el cual Lechner (1990) escribió a propósito de subjetividad y política y el contexto actual en Centroamérica, no dejan de existir similitudes. Dice Lechner:

La fuerza de lo necesario aumenta incesantemente, mientras que se ha debilitado nuestra capacidad político-cultural de redefinir lo posible y, con mayor razón, lo deseable. No es que existan menos posibilidades o menos anhelos; ellos crecen al igual que las necesidades, mas no encuentran un marco interpretativo... Para realizar reformas políticas necesitamos realizar, ante todo, una reforma de la política. Ello implica mirar más allá de la política (institucional)... A menudo se analiza la dinámica institucional, la estrategia de actores y los condicionantes económicos sin considerar debidamente la experiencia diaria de la gente, sus miedos y sus deseos. Las callejuelas de la vida cotidiana son frecuentemente callejones sin salida, pero a veces permiten vislumbrar la cara oculta de las grandes avenidas (pp. 14-15).

\section{Consideraciones metodológicas}

A partir de lo que se conoce como juicio experto, personas conocedoras de la región centroamericana sugirieron posibles colonias $y$, a partir de ello, se iniciaron los contactos. Las colonias seleccionadas guardan factores en común, por ejemplo, condiciones de pobreza y estigmatización social. Así, se eligieron: El Limón, en Ciudad de Guatemala; Popotlán, en San Salvador; Nueva Capital, en Tegucigalpa; Jorge Dimitrov, en Managua, y La Carpio, en San José.

La muestra se construyó a partir del criterio de cuotas. Se trata de una muestra representativa no aleatoria (Hernández, Fernández y Baptista, 2014), cuyos resultados se pueden extrapolar al conjunto de la población seleccionada residente en la colonia. Un primer paso fue identificar características demográficas de las comunidades o colonias seleccionadas (en caso de no contar con datos desagregados de las comunidades, se emplearon datos de áreas geográficas más grandes).

Posteriormente, se determinó aplicar 300 encuestas por colonia, a partir de criterios de conveniencia y recursos financieros. Las cuotas se distribuyeron según tres variables: edad (14 a 17 y 18 a 24 años), sexo (hombre $y$ mujer) y si estudia o trabaja. Las 300 encuestas por comunidad se distribuyeron, entonces, en combinaciones de estas tres variables, lo cual dio origen a ocho subgrupos. Las personas mayores de edad firmaron un consentimiento informado; en el caso de las menores, el consentimiento lo firmaron también personas responsables de ellos y ellas. En el Anexo, se incluye la distribución de la muestra y el cuestionario.

Para cada comunidad, se consiguió un mapa que permitiera decidir la selección de las viviendas. En cada caso, se tomaron lugares de referencia para iniciar y se avanzó siguiendo la orientación de las agujas del reloj. En el caso de El Salvador, la encuesta no se realizó de manera domiciliar por razones de seguridad, pues el control territorial que 
ejercen las pandillas impide transitar por sectores de la colonia controlados por una pandilla diferente. En su lugar, la encuesta se organizó en puntos centrales, tales como centros educativos y sectores específicos de la colonia Popotlán, en donde el equipo encuestador tenía acceso, pues son sus sitios de residencia.

Luego de los contactos iniciales en cada colonia, se invitó a jóvenes de las comunidades a formar parte del equipo encuestador. La selección y preparación de los equipos demandó reuniones constantes, a fin de entrar en contacto, apropiarse de los objetivos del estudio y conocer en detalle el cuestionario. Ello supuso una labor de coordinación y conocimiento mutuo que permitiera un trabajo sistemático y cuidadoso. Se realizaron varias reuniones preparatorias con los respectivos equipos, de modo que se pudieran familiarizar con aspectos de la muestra, el cuestionario y el trabajo de campo.

El trabajo de campo se organizó a partir de una hoja de cuota, en donde se especificaba la cantidad de casos según edad, sexo y actividad (estudio o trabajo) de las personas y se iban anotando las encuestas realizadas, hasta completar 300 casos. El trabajo se inició en La Carpio, continuó en las colonias Jorge Dimitrov, Popotlán, Nueva Capital y El Limón, entre junio y noviembre del año 2017. En cada comunidad, se laboró de manera intensiva entre tres y cinco días y las personas encuestadoras, alrededor de cien, fueron remuneradas por cada cuestionario debidamente completado.

\section{Resultados}

La exclusión primaria: empleo y oportunidades

Un $76.4 \%$ de las personas encuestadas no tiene empleo remunerado. Del total de las mujeres, un $80.3 \%$ no tiene empleo; para el caso de los hombres, el porcentaje es $72 \%$, tal como se detalla en la Tabla 1. Popotlán reporta un desempleo de un 82.7 \% y Jorge Dimitrov un $70.7 \%$, es decir, las diferencias no son acentuadas entre la colonia con más desempleo y la que reporta el menor porcentaje. Si se desagrega la información por edades, un $56.5 \%$ de quienes tienen entre 21 y 24 años, un periodo de la vida en donde se esperaría que se inicia la vida laboral, no trabaja de manera remunerada.

Tabla 1

Distribuciones de frecuencia y porcentajes de personas con empleo remunerado en los países de Centroamérica según sexo

\begin{tabular}{lcccc}
\hline \multirow{2}{*}{ País } & \multicolumn{4}{c}{ Trabajo remunerado } \\
\cline { 2 - 5 } & \multicolumn{3}{c}{ Mujeres } & \multicolumn{3}{c}{ Hombres } \\
\cline { 2 - 5 } & Frecuencia & Porcentaje & Frecuencia & Porcentaje \\
\hline El Limón & 34 & 21 & 47 & 24 \\
Nueva Capital & 25 & 16 & 30 & 16 \\
Popotlán & 27 & 17 & 25 & 13 \\
Jorge Dimitrov & 42 & 27 & 46 & 23 \\
La Carpio & 30 & 19 & 48 & 24 \\
\hline
\end{tabular}

Fuente: Demandas ciudadanas de jóvenes residentes en barriadas populares en Centroamérica. Un estudio exploratorio regional, 2017. 
Un $37.7 \%$ de las personas encuestadas no estudia ni trabaja, es decir, quienes no estudian encuentran también muy difícil contar con un empleo remunerado. Entre quienes tienen entre 18 y 20 años, el porcentaje que no estudia ni trabaja alcanza un $38.4 \%$. Sobre este grupo, en torno al cual incluso se emplea la expresión despectiva y desafortunada de "ninis", es más manifiesta la ausencia de oportunidades.

Al carecer de empleo, también se suele carecer de acceso a la seguridad social, como se aprecia en la Tabla 2, pues apenas un $15 \%$ respondió contar con seguro social, un $60.7 \%$ no cuenta con aseguramiento y un $24.3 \%$ no sabe o no respondió. Es decir, la ausencia de aseguramiento alcanza proporciones cercanas al desempleo. Las personas que responden que no saben o no responden son más entre quienes tienen entre 14 y 17 años (31.5\%), lo cual disminuye conforme aumenta la edad, de manera que el grupo entre 20 y 24 años es el que menos presenta este tipo de respuestas (14.3\%).

Tabla 2

Distribuciones porcentuales de los que poseen seguro según sexo y comunidad de residencia

\begin{tabular}{lcccc}
\hline \multirow{2}{*}{\multicolumn{1}{c}{ País }} & \multicolumn{2}{c}{ Posee seguro } & \multicolumn{2}{c}{ No posee seguro } \\
\cline { 2 - 5 } & Mujer & Hombre & Mujer & Hombre \\
\hline El Limón & 15 & 19 & 27 & 26 \\
Nueva Capital & 15 & 8 & 29 & 29 \\
Popotlán & 24 & 17 & 26 & 25 \\
Jorge Dimitrov & 9 & 17 & 13 & 12 \\
La Carpio & 37 & 39 & 5 & 8 \\
\hline
\end{tabular}

Fuente: Demandas ciudadanas de jóvenes residentes en barriadas populares en Centroamérica. Un estudio exploratorio regional, 2017.

Aunque la encuesta no puede explicar lo anterior, las diferencias en las respuestas según edades posiblemente se deban a que quienes se sitúan entre los 14 y 17 requieren en menor medida de servicios médicos y no suelen conocer los criterios de acceso a estos. Las diferencias de acceso entre hombres y mujeres no varían mucho en la muestra total, pues un $59 \%$ de las mujeres reporta no tener seguro y un $62.6 \%$ manifiesta tenerlo.

Sin embargo, cuando se desagrega por sexo y edad, los resultados varían. Entre quienes tienen entre 21 y 24 años, un $21.4 \%$ de las mujeres reportan tener seguro social, mientras que un $30.5 \%$ de los hombres lo tienen. En este mismo grupo de edad, son más las mujeres que responden que no saben, o bien, que no responden si tienen seguro, en relación con los hombres
(18.4\% y $8.4 \%$, respectivamente). Estas diferencias entre hombres y mujeres podrían estar evidenciando que los empleos de las mujeres incluyen menos aseguramiento que los que adquieren los hombres.

El escaso acceso a servicios de salud tiene consecuencias prácticas en la vida de las personas. La encuesta consultó por situaciones difíciles que han sido experimentadas por la persona o su familia en los últimos 12 meses. En ese sentido, las "enfermedades" alcanzan el mayor porcentaje (46\%), incluso por encima de la violencia criminal, pues los robos sin violencia registran un $23 \%$ y los robos con violencia un $13 \%$.

A las dificultades del acceso en términos de afiliación y derechos, se suma la ausencia de clínicas cercanas. En Nueva Capital y en otras pequeñas colonias vecinas, por ejemplo, 
viven alrededor de 60,000 personas, quienes no tienen agua potable y se ven obligadas a recoger agua llovida en tambos, lo cual produce una alta incidencia de zika y con esta de microcefalia. Además, no hay clínica local de salud y la secundaria es una iniciativa de un sacerdote visionario, no del Estado. Es decir, la violencia estructural está profundamente enraizada en la vida cotidiana de las colonias.

\section{Aún más difícil para las mujeres}

Un poco más de la mitad de las personas encuestadas estudian (52.1\%). En el caso de los hombres, el porcentaje es muy semejante al de los que no estudian (49.1\% y $45.3 \%$ ). Ello no ocurre en el caso de las mujeres, pues un $45.3 \%$ estudia y un $54.8 \%$ no lo hace. Como la literatura sobre género y pobreza muestra (Batthyány et al., 2005), la ausencia de oportunidades es aún más estructural en el caso de las mujeres.

En las cinco comunidades, las mujeres que no estudian son más que quienes estudian; la excepción es La Carpio, en Costa Rica, tal y como se aprecia en la Tabla 3. Nueva Capital es el caso más extremo, pues un $76.1 \%$ de las mujeres y un $75.2 \%$ de los hombres no estudian. Estos resultados permiten comprender por qué Honduras es el país donde más personas se ven obligadas a emigrar en los últimos años, como se anotó antes a propósito de los resultados de los censos de los Estados Unidos.

Tabla 3

Distribuciones porcentuales de los que estudian en la actualidad según sexo y país de residencia

\begin{tabular}{lcc}
\hline País & \multicolumn{2}{c}{ Estudia } \\
\cline { 2 - 3 } El Limón & Mujer & Hombre \\
\cline { 2 - 3 } Nueva Capital & 43 & 49 \\
Popotlán & 24 & 25 \\
Jorge Dimitrov & 48 & 60 \\
La Carpio & 52 & 67 \\
\hline
\end{tabular}

Fuente: Demandas ciudadanas de jóvenes residentes en barriadas populares en Centroamérica. Un estudio exploratorio regional, 2017.

En cuanto a la paternidad y maternidad, un $22 \%$ de la población encuestada es madre o padre. El porcentaje de mujeres que son madres (32\%) casi triplica el porcentaje de hombres que son padres (13\%). Un $45.96 \%$ de las mujeres fueron mamás antes de cumplir los 18 años, es decir, cerca de la mitad de ellas. Por su parte, un $22 \%$ de los hombres que son padres lo fueron por primera vez antes de cumplir los 18 años. Es decir, la cantidad de mujeres madres es bastante mayor que el de los hombres y ellas lo son a una edad mucho más temprana. Maternidades y paternidades tempranas disminuyen la posibilidad de mantenerse en la educación formal y reduce las oportunidades de un mejor futuro. De hecho, apenas un $18 \%$ de quienes son padres o madres estudian.

Por la misma cultura patriarcal, pudo darse que los hombres no hayan reportado su condición de padres, pero la encuesta no podía detectar eso. Más allá de ello, es urgente la educación en la afectividad y la sexualidad. Es decir, las dimensiones, si se quiere más "materiales" o "estructurales", como el empleo, deben ir en una relación recíproca con las dimensiones más culturales y 
subjetivas. No es lo uno o lo otro, sino su relación y complementariedad (Fraser, 2013).

\section{Cómo nos ven, cómo nos vemos}

Los demás nos devuelven una imagen de nosotros mismos que tiende a tener un peso importante en nuestra autopercepción, tanto si es negativa o positiva, en términos si se quiere más individuales o más colectivos (Úriz, 1993).

Dos de las preguntas de la encuesta propusieron una serie de afirmaciones, tal y como se reporta en la Tabla 4. En un caso, se les solicitó a las personas que las ordenaran según la importancia que tenían para las personas que vivían fuera de la colonia y, en el otro caso, según la importancia para las personas de la colonia.

Tabla 4

Preferencia* promedio basada en la opinión de cómo se consideran las personas de la comunidad desde afuera y desde adentro, según comunidad de residencia

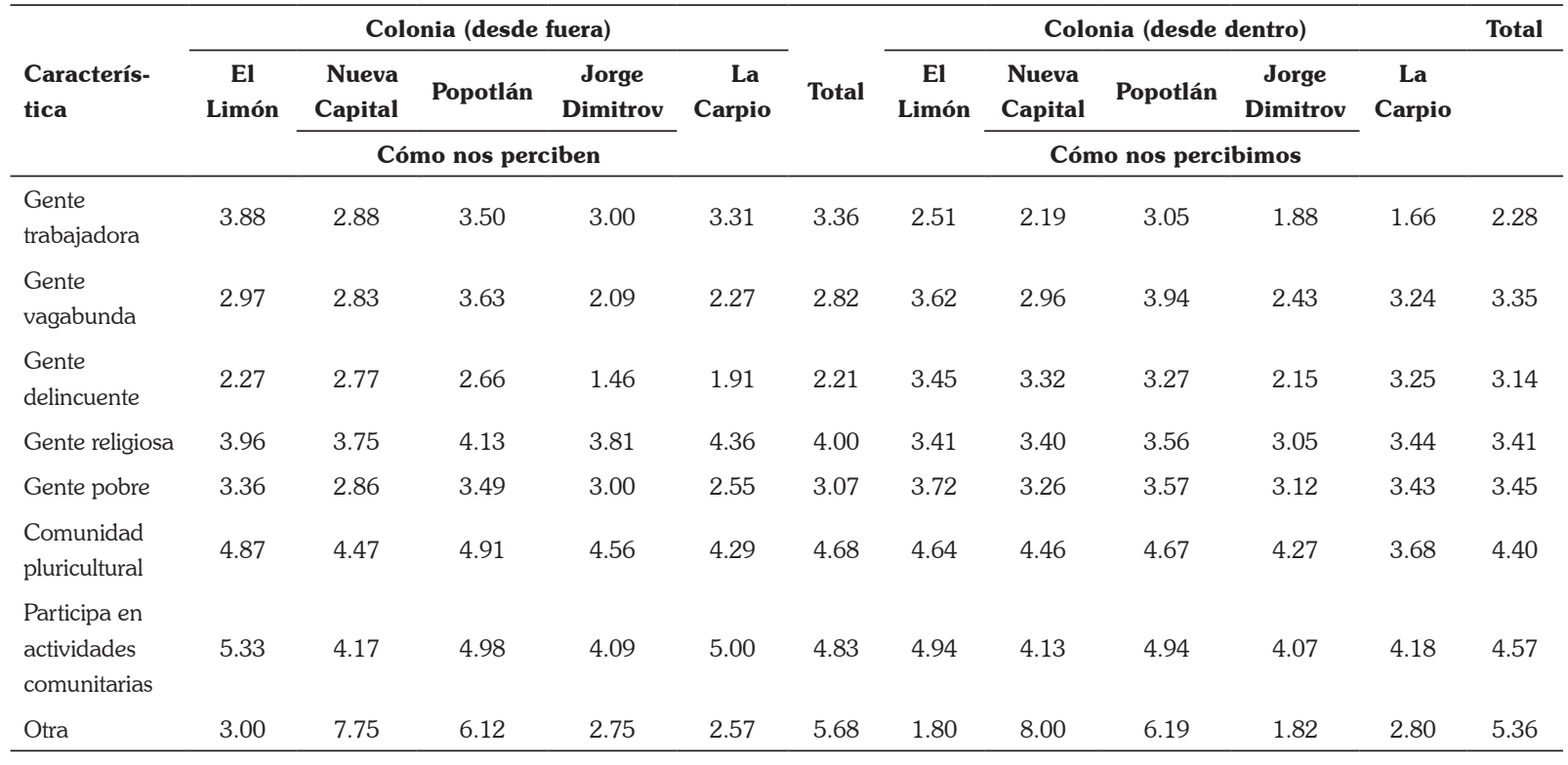

Fuente: Demandas ciudadanas de jóvenes residentes en barriadas populares en Centroamérica. Un estudio exploratorio regional, 2017.

*Orden de preferencia donde 1 es el más preferido y 10 , el menos preferido.

Como se aprecia en la Tabla 4, desde fuera, las imágenes predominantes son "gente delincuente" y "gente vagabunda"; mientras tanto, "gente trabajadora" es la más frecuente desde dentro, es decir, la más cercana a 1. Las referencias a delincuencia y vagabundería confirman la tendencia hacia la estigmatización y criminalización, tan frecuentemente asociadas a comunidades empobrecidas. "Gente trabajadora" registra la mayor discre- pancia entre la auto y la hetero percepción (1.08 \%); la primera es más cercana a 1.

Para las personas que viven en Jorge Dimitrov (1.46 \%) y La Carpio (1.9 \%), "gente delincuente" son imágenes frecuentes empleadas por quienes no residen allí y disminuyen cuando se consulta por la opinión de quienes residen en las respectivas colonias. La afirmación "gente vagabunda" presenta 
una identificación menos intensa, aunque es también en Jorge Dimitrov (2.05\%) y La Carpio $(2.27 \%)$ donde la frase se asume como una representación predominante de quienes no viven en dichas colonias. Cuando se consulta en qué medida esta imagen es empleada al interior de la comunidad, la asociación disminuye, aunque en Jorge Dimitrov la prevalencia de la imagen es más alta $(2.43 \%)$. "Gente delincuente" y "gente vagabunda" son pues las imágenes despectivas que serían más frecuentes entre quienes no viven en las colonias, registradas por residentes de dichas colonias.

Los resultados muestran que las personas encuestadas no consideran que quienes no viven en las colonias donde ellas residen les consideren como "gente trabajadora". El promedio total es de $3.36 \%$ y solo en el caso de Nueva Capital (2.87 \%) el porcentaje es menor a $3 \%$. Mientras tanto, cuando se consulta sobre en qué medida las personas de las colonias se consideran "gente trabajadora" el promedio es 2.28 \%. Incluso los porcentajes son más favorables en La Carpio y Jorge Dimitrov, con 1.66 \% y $1.87 \%$, respectivamente.

Como se anotó antes, los porcentajes de No sabe/No responde (NS/NR) son altos, tanto en las respuestas sobre las opiniones de las personas externas a las colonias, como en aquellas referidas al parecer de quienes viven en estas. En los casos de "gente criminal" y "gente delincuente" los porcentajes son más altos cuando la consulta se refiere a la prevalencia de estas imágenes dentro de la comunidad (34.8 \%, 15.7 \%, 38 \%, $26.4 \%$, respectivamente). Es decir, las personas estarían evitando emplear una imagen negativa cuando se trata de autodescribirse. La relación de (NS/NR) se invierte cuando se trata de "gente trabajadora" (17.3 \% y $34.6 \%$, respectivamente); en este caso, las no respuestas aumentan cuando se consulta sobre la imagen que tienen los otros.
El reconocimiento de la desigualdad

Cuando la pregunta se refiere al principal problema del país, los temas de criminalidad (delincuencia, violencia, pandillas y drogas) ocupan el primer lugar con un $34 \%$, seguidos de desempleo (20\%), corrupción (12\%), falta de apoyo gubernamental (9 \%) y pobreza (5 \%). La criminalidad sobresale tanto en el plano comunitario (55.4\%), como en el nacional (34\%).

Dado que la criminalidad es el problema más reconocido, se consultó sobre la percepción de miedo de ser víctima de violencia, para lo cual se empleó una escala que distinguía "mucho miedo", "miedo", "poco miedo" y "nada de miedo". Las respuestas indican que un tercio de las personas sienten "mucho miedo" y "miedo" (36 \%), otro tercio percibe "poco miedo" (31 \%) y un tercio percibe "nada de miedo" (33 \%). Las mujeres perciben más "mucho miedo" que los hombres (22.4\% y $15.5 \%$, respectivamente). A su vez, los hombres perciben más "nada de miedo" que las mujeres (38.5\% y $27.3 \%$, respectivamente).

Como se observa en la Tabla 5 , si se suman las tres opciones, "mucho miedo", "miedo" y un "poco de miedo", el miedo es una experiencia ampliamente extendida $e$ incluso alcanza $78 \%$ en El Limón y $82 \%$ en Popotlán. Si bien Nueva Capital está situada en Tegucigalpa, una de las ciudades con una mayor tasa de homicidio doloso, no reporta una experiencia de miedo tan acentuada, al menos durante el periodo de encuesta, lo cual advierte acerca de la importancia de no realizar generalizaciones apresuradas y de no considerar que la pobreza es por sí misma un factor desencadenador de la criminalidad y con ella del miedo. En otras palabras, se requieren análisis que presten atención a factores contextuales, desde los cuales toman forma los factores, si se quiere, más estructurales. 
Tabla 5

Distribuciones porcentuales de la percepción del miedo en los últimos 12 meses de ser víctimas de violencia en la comunidad según país de residencia

\begin{tabular}{lccccc}
\hline \multirow{2}{*}{ País } & \multicolumn{5}{c}{ Nivel } \\
\cline { 2 - 5 } & Mucho miedo & Miedo & Poco miedo & Nada de miedo & NS/NR \\
\hline El Limón & 32 & 20 & 26 & 22 & 0 \\
Nueva Capital & 13 & 16 & 31 & 39 & 1 \\
Popotlán & 22 & 24 & 36 & 17 & 0 \\
Jorge Dimitrov & 13 & 12 & 30 & 44 & 1 \\
La Carpio & 15 & 13 & 30 & 41 & 0 \\
Total & 19 & 17 & 31 & 32 & 0 \\
\hline
\end{tabular}

Fuente: Demandas ciudadanas de jóvenes residentes en barriadas populares en Centroamérica. Un estudio exploratorio regional, 2017.

Junto con la percepción del miedo, un segundo tema de relevancia es la percepción de la desigualdad. Esta fue una de las preguntas que reporta hallazgos más contundentes: un $73.6 \%$ de las personas encuestadas consideran que en sus respectivos países la distribución de la riqueza es "muy injusta" o un "poco injusta". Las respuestas no dan cuenta de diferencias sustantivas por género. Como se aprecia en la Tabla 6, en Popotlán, el "muy injusta" y un "poco injusta" alcanzan un 88 \% y en El Limón un $81 \%$. En Nueva Capital, Jorge Dimitrov y La Carpio, los porcentajes de ambas opciones suman $74 \%$, $58 \%$ y $65 \%$, respectivamente.

Tabla 6

Distribuciones porcentuales de la percepción de la repartición de la riqueza según comunidad de residencia

\begin{tabular}{lcccccc}
\hline Comunidad & Muy injusta & $\begin{array}{c}\text { Un poco } \\
\text { injusta }\end{array}$ & $\begin{array}{c}\text { Ni justa ni } \\
\text { injusta }\end{array}$ & $\begin{array}{c}\text { Un poco } \\
\text { justa }\end{array}$ & Muy justa & NS/NR \\
\hline El Limón & 62 & 20 & 6 & 7 & 4 & 1 \\
Nueva Capital & 51 & 23 & 9 & 9 & 8 & 1 \\
Popotlán & 64 & 24 & 8 & 4 & 0 & 1 \\
Jorge Dimitrov & 32 & 26 & 10 & 19 & 5 & 7 \\
La Carpio & 37 & 29 & 14 & 12 & 6 & 1 \\
Total & 49 & 24 & 9 & 10 & 5 & 2 \\
\hline
\end{tabular}

Fuente: Demandas ciudadanas de jóvenes residentes en barriadas populares en Centroamérica. Un estudio exploratorio regional, 2017. 
Pérdida de legitimidad de las instituciones

Los resultados muestran una muy baja confianza en las instituciones. Como se aprecia en la Tabla 7, todas las instituciones reciben una calificación inferior a 7 . Incluso los tres poderes de la república, el legislativo, el ejecutivo y el judicial, reciben $3.7 \%, 4.5 \%$ y $4.7 \%$, respectivamente. Solo las universi- dades y las instituciones educativas obtienen una calificación mayor a 7 (7.5 \% y 7.7\%, respectivamente). En comunidades en donde un $76.4 \%$ de las personas encuestadas no tienen empleo remunerado y un $37.7 \%$ no estudia ni trabaja, se anhelan las oportunidades educativas que no se han tenido.

Tabla 7

Escala promedio de la confianza hacia las diferentes instituciones según país de residencia (escala de 1 a 10)*

\begin{tabular}{lcccccc}
\hline Institución & El Limón & $\begin{array}{c}\text { Nueva } \\
\text { Capital }\end{array}$ & Popotlán & $\begin{array}{c}\text { Corge } \\
\text { Dimitrov }\end{array}$ & La Carpio & Total \\
\hline Iglesia católica & 5.6 & 5.6 & 6.7 & 4.5 & 4.9 & 5.5 \\
Iglesia no católica & 7.1 & 6.9 & 6.5 & 6.9 & 6.4 & 6.7 \\
Gobierno central & 3.9 & 3.9 & 4.7 & 5.2 & 4.7 & 4.5 \\
Alcaldía de su municipio & 4.5 & 4.4 & 5.5 & 6.1 & 5.1 & 5.1 \\
Asamblea de diputados & 3.0 & 3.0 & 4.0 & 4.2 & 4.1 & 3.7 \\
Universidades & 7.1 & 6.4 & 7.7 & 7.8 & 8.4 & 7.5 \\
Empresa privada & 5.1 & 5.1 & 5.2 & 5.4 & 5.9 & 5.3 \\
Medios de & 6.6 & 6.8 & 6.5 & 7.2 & 7.6 & 6.9 \\
comunicación & 3.6 & 3.5 & 4.7 & 4.8 & 4.9 & 4.3 \\
Sindicatos & 4.7 & 4.7 & 5.0 & 4.6 & 5.3 & 4.9 \\
Policía municipal & 4.3 & 4.9 & 5.3 & 6.1 & 5.3 & 5.2 \\
Polić́a nacional & 5.8 & 5.7 & 5.5 & 6.0 & 4.9 & 5.7 \\
Ejército & 3.0 & 3.5 & 4.0 & 4.6 & 4.2 & 3.9 \\
Partidos políticos & 4.1 & 4.7 & 4.5 & 6.0 & 4.8 & 4.8 \\
Alcalde de su municipio & 4.3 & 3.7 & 4.7 & 5.0 & 5.4 & 4.7 \\
Jueces & 7.0 & 7.6 & 7.5 & 7.9 & 8.3 & 7.7 \\
Centros educativos & & & & & \\
\hline
\end{tabular}

Fuente: Demandas ciudadanas de jóvenes residentes en barriadas populares en Centroamérica. Un estudio exploratorio regional, 2017. *Escala de 1 a 10, donde 1 es pésimo y 10 es excelente.

En este contexto de una muy baja confianza en las instituciones, las Iglesias no católicas $(6.7 \%)$ superan a la mayoría de las instituciones, incluida a la misma Iglesia católica (5.5\%), a los poderes del Estado y a la empresa privada.
Junto con la valoración de la confianza, también se analizó la participación. Los grupos en que las personas más participan son los deportivos (43\%), de Iglesias cristianas (40\%), grupos culturales $(20 \%)$ y grupos de la Iglesia católica (18\%), como se anota en la Tabla 8. De nuevo emerge el 
protagonismo de la participación en grupos de

Iglesias cristianas.

Tabla 8

Distribuciones porcentuales de la participación en las diferentes instituciones o grupos según país de residencia

\begin{tabular}{|c|c|c|c|c|c|c|c|c|c|c|}
\hline País & Deportivos & $\begin{array}{l}\text { Iglesia } \\
\text { cristiana }\end{array}$ & $\begin{array}{c}\text { Grupos } \\
\text { culturales }\end{array}$ & $\begin{array}{l}\text { Iglesia } \\
\text { católica }\end{array}$ & $\begin{array}{c}\text { Grupos } \\
\text { musicales }\end{array}$ & $\begin{array}{c}\text { Movimientos } \\
\text { sociales }\end{array}$ & $\begin{array}{l}\text { Partidos } \\
\text { políticos }\end{array}$ & Ejército & $\begin{array}{c}\text { Policía } \\
\text { Municipal }\end{array}$ & Sindicatos \\
\hline El Limón & 42 & 51 & 16 & 22 & 18 & 14 & 4 & 4 & 4 & 2 \\
\hline Jorge Dimitrov & 34 & 43 & 17 & 12 & 11 & 8 & 7 & 1 & 2 & 1 \\
\hline Nueva Capital & 43 & 39 & 10 & 17 & 8 & 8 & 9 & 4 & 1 & 0 \\
\hline La Carpio & 48 & 37 & 28 & 16 & 20 & 10 & 10 & 0 & $0^{*}$ & 0 \\
\hline Popotlán & 48 & 31 & 28 & 22 & 19 & 10 & 3 & 1 & 1 & 1 \\
\hline Total & 43 & 40 & 20 & 18 & 15 & 10 & 7 & 2 & 2 & 2 \\
\hline
\end{tabular}

Fuente: Demandas ciudadanas de jóvenes residentes en barriadas populares en Centroamérica. Un estudio exploratorio regional, 2017.

*Valores redondeados, valor real 0.3 .

La participación en Iglesias cristianas es superior en el caso de las mujeres (57.5\%). En El Limón y Jorge Dimitrov, la participación supera el promedio con $50.8 \%$ y $42.7 \%$, respectivamente. Los resultados obtenidos en El Limón no son del todo sorprendentes si se toma en cuenta el auge neopentecostal en Guatemala, que constituye uno de los países en donde la membresía de las Iglesias cristianas pronto superará al de la misma Iglesia católica (Cantón, 1998).

Entre quienes participan en la Iglesia católica, la distribución entre hombres y mujeres es muy semejante a los porcentajes registrados en las Iglesias cristianas (56\% y $43 \%$, respectivamente). Ello es muy relevante, pues la división por género se mantiene, es decir, las prácticas religiosas mantienen una estruc- tura semejante, aunque se trate de Iglesias diferentes.

Rasgos de autoritarismo y erosión de la democracia

La encuesta que sirve de base a este artículo también exploró representaciones de autoridad entre las personas encuestadas (Adorno et al., 1959). En ese sentido, se formularon cuatro afirmaciones: "Obedecer a las autoridades del gobierno, aunque no tengan razón"; "La mano dura va a acabar con los problemas del país"; "Todos tenemos un destino que no depende de nosotros"; "Obedecer a los padres, aunque no se hayan ganado el respeto", para las cuales se ofrecía cinco posibilidades de respuesta, tal y como se muestra en la Tabla 9. 
Tabla 9

Distribuciones porcentuales de qué tan de acuerdo están las personas con las distintas afirmaciones según comunidad de residencia

\begin{tabular}{|c|c|c|c|c|c|c|}
\hline & \multirow[b]{2}{*}{ Afirmación } & \multicolumn{5}{|c|}{ Comunidad } \\
\hline & & El Limón & $\begin{array}{l}\text { Nueva } \\
\text { Capital }\end{array}$ & Popotlán & $\begin{array}{c}\text { Jorge } \\
\text { Dimitrov }\end{array}$ & La Carpio \\
\hline \multirow{6}{*}{$\begin{array}{l}\text { Obedecer a las } \\
\text { autoridades del } \\
\text { gobierno, aunque } \\
\text { no tengan razón }\end{array}$} & Muy de acuerdo & 14.0 & 10.7 & 10.0 & 7.0 & 7.9 \\
\hline & De acuerdo & 18.7 & 25.0 & 26.0 & 23.0 & 15.9 \\
\hline & En desacuerdo & 26.1 & 40.0 & 36.0 & 35.3 & 45.7 \\
\hline & Muy en desacuerdo & 29.8 & 20.3 & 23.7 & 24.0 & 20.9 \\
\hline & Ni de acuerdo ni en desacuerdo & 10.4 & 4.0 & 4.3 & 7.3 & 8.9 \\
\hline & NS/NR & 1.0 & 0.0 & 0.0 & 3.3 & 0.7 \\
\hline \multirow{7}{*}{$\begin{array}{l}\text { Obedecer a los } \\
\text { padres, aunque no } \\
\text { se hayan ganado } \\
\text { el respeto }\end{array}$} & & 52.5 & 44.0 & 38.7 & 32.0 & 26.5 \\
\hline & Muy de acuerdo & & & & & \\
\hline & De acuerdo & 30.4 & 42.0 & 43.3 & 51.7 & 44.4 \\
\hline & En desacuerdo & 9.4 & 10.0 & 13.3 & 9.7 & 18.2 \\
\hline & Muy en desacuerdo & 2.7 & 3.0 & 3.3 & 3.7 & 4.0 \\
\hline & Ni de acuerdo ni en desacuerdo & 4.0 & 0.3 & 1.3 & 2.0 & 6.0 \\
\hline & NS/NR & 1.0 & 0.7 & 0.0 & 1.0 & 1.0 \\
\hline \multirow{7}{*}{$\begin{array}{l}\text { Todos tenemos } \\
\text { un destino que } \\
\text { no depende de } \\
\text { nosotros }\end{array}$} & & 38.8 & 28.3 & 22.3 & 15.0 & 15.6 \\
\hline & Muy de acuerdo & & & & & \\
\hline & De acuerdo & 25.4 & 35.3 & 38.3 & 43.3 & 32.8 \\
\hline & En desacuerdo & 18.1 & 21.0 & 23.7 & 19.0 & 25.8 \\
\hline & Muy en desacuerdo & 10.0 & 11.7 & 12.0 & 14.0 & 15.9 \\
\hline & Ni de acuerdo ni en desacuerdo & 5.4 & 2.3 & 2.7 & 2.7 & 7.3 \\
\hline & NS/NR & 2.3 & 1.3 & 1.0 & 6.0 & 2.6 \\
\hline \multirow{7}{*}{$\begin{array}{l}\text { La mano dura va } \\
\text { a acabar con los } \\
\text { problemas del país }\end{array}$} & & 21.1 & 23.3 & 20.0 & 14.3 & 18.5 \\
\hline & Muy de acuerdo & & & & & \\
\hline & De acuerdo & 15.7 & 31.7 & 20.7 & 40.3 & 34.1 \\
\hline & En desacuerdo & 22.7 & 24.3 & 28.7 & 20.3 & 23.2 \\
\hline & Muy en desacuerdo & 24.4 & 14.0 & 26.3 & 14.0 & 10.6 \\
\hline & Ni de acuerdo ni en desacuerdo & 12.4 & 4.7 & 3.7 & 4.0 & 10.9 \\
\hline & NS/NR & 3.7 & 2.0 & 0.7 & 7.0 & 2.6 \\
\hline
\end{tabular}

Fuente: Demandas ciudadanas de jóvenes residentes en barriadas populares en Centroamérica. Un estudio exploratorio regional, 2017.

De las cuatro afirmaciones, la única que no alcanzó apoyo fue "Obedecer a las autoridades del gobierno, aunque no tengan razón", pues apenas un $31.6 \%$ estuvo "totalmente de acuerdo" o "de acuerdo". El apoyo más débil se obtuvo en La Carpio, donde apenas un 23.8 \% la apoyó. Es decir, el Gobierno es la única forma de autoridad que se cuestiona 
en forma explícita. Más que una relación si se quiere crítica y reflexiva hacia las autoridades y el poder, estas respuestas parecen confirmar la erosión de la legitimidad de la democracia como forma de organización política, como se retomará más adelante.

"La mano dura va a acabar con los problemas del país" divide las respuestas. Un $48 \%$ está "muy en desacuerdo" o "en desacuerdo" y un $41.8 \%$ la apoya; quienes no están ni de acuerdo ni en desacuerdo suman un 7.1 \%. Los mayores desacuerdos se registran en Popotlán, con un $55 \%$, una colonia que ha vivido la puesta en práctica de estas políticas registra el menor apoyo (Asmann, 2017).

La afirmación "Todos tenemos un destino que no depende de nosotros" recibió apoyo ("muy de acuerdo" o "de acuerdo") en todas las colonias, desde un $48.4 \%$ en La Carpio, hasta un $63.6 \%$ en Nueva Capital y un $64.2 \%$ en El Limón. "Obedecer a los padres, aunque no se hayan ganado el respeto" recibió el mayor apoyo entre las personas consultadas, pues un $81.1 \%$ está "de acuerdo" o "muy de acuerdo" con la afirmación. En este caso, como en los anteriores, las diferencias en las respuestas de hombres y mujeres son mínimas. En todas las comunidades, el apoyo fue alto: en La Carpio recibió un $70.9 \%$ y un $86 \%$ en Nueva Capital. La autoridad de los padres constituiría una referencia poco cuestionada incluso si no procedieran bien, pues se asume que su legitimidad no admite críticas.

La encuesta también interrogó por la adscripción de las personas encuestadas a la democracia como forma de organización política. Para ello, se les propuso una serie de frases y se les solicitó que seleccionaran una de ellas, es decir, era selección única. Estas frases fueron: "En algunos casos, un gobierno autoritario es preferible a uno democrático", "Un gobierno democrático es preferible a cualquier otro tipo de gobierno", "A la gente como uno, da lo mismo un gobierno democrático que uno autoritario" y "No importa si es o no democrático, lo importante es que resuelva los problemas".

La última afirmación, "No importa si es o no democrático, lo importante es que resuelva los problemas", agrupa un $71.48 \%$ de las respuestas. Un $74.5 \%$ de las mujeres y un $68.0 \%$ de los hombres eligieron esta opción. La distribución de las respuestas entre las colonias es homogénea; en La Carpio recibe menos apoyo (62.6 \%) y en Jorge Dimitrov tiene más aceptación (76.7 \%). Incluso, en las colonias Jorge Dimitrov (76.7 \%), Popotlán (74.3 \%) y Nueva Capital (73.7 \%), el apoyo supera el promedio de la muestra. El porcentaje más bajo se encuentra en La Carpio con un $62.6 \%$, que no deja de expresar una opinión que recibe apoyo de la mayoría.

Muy lejos aparece la afirmación "Un gobierno democrático es preferible a cualquier otro tipo de gobierno" con un $13.05 \%$. Un $11.6 \%$ de las mujeres y un $14.7 \%$ de los hombres eligieron esta opción. Un $33.7 \%$ de las personas que eligieron viven en La Carpio; mientras tanto en Jorge Dimitrov y Popotlán apenas alcanzó un $10 \%$ en cada una de las colonias (Tabla 10). 
Tabla 10

Distribuciones porcentuales de las frases con las que más se identifican las personas según comunidad de residencia

\begin{tabular}{lccccc}
\hline & \multicolumn{4}{c}{ Comunidad } \\
\cline { 2 - 5 } Frase & El Limón & Nueva Capital & Popotlán & $\begin{array}{c}\text { Jorge } \\
\text { Dimitrov }\end{array}$ & La Carpio \\
\hline $\begin{array}{l}\text { Gobierno autoritario preferible } \\
\text { al democrático }\end{array}$ & 34.5 & 15.5 & 13.8 & 10.3 & 25.9 \\
$\begin{array}{l}\text { Gobierno democrático preferible } \\
\text { a cualquier otro gobierno }\end{array}$ & 16.3 & 19.4 & 15.3 & 15.3 & 33.7 \\
$\begin{array}{l}\text { Da lo mismo un gobierno demo- } \\
\text { crático que uno autoritario }\end{array}$ & 21.1 & 21.1 & 26.3 & 13.2 & 18.4 \\
$\begin{array}{l}\text { No importa si es o no demo- } \\
\text { crático, pero que resuelva los }\end{array}$ & 19.6 & 20.6 & 20.8 & 21.4 & 17.6 \\
problemas & & & & & \\
NS/NR & 21.7 & 13.3 & 15.0 & 31.7 & 18.3 \\
\hline
\end{tabular}

Fuente: Demandas ciudadanas de jóvenes residentes en barriadas populares en Centroamérica. Un estudio exploratorio regional, 2017.

La urgencia de oportunidades y la ausencia de respuestas por parte de las instituciones tienen consecuencias en términos de avalar propuestas que ofrezcan soluciones largamente postergadas. Es este contexto en el cual los llamados "outsiders" de la política - comediantes, animadores de televisión, entre otros- cautivan a sectores mayoritarios, a menudo echando mano de discursos religiosos neopentecostales, lo cual tampoco sería de extrañar, pues las iglesias, como ya se anotó, son de las pocas instituciones presentes en las comunidades.

\section{Desplazamiento forzado}

Como parte de las valoraciones sobre el territorio y las expectativas a futuro, se les consultó a las personas encuestadas si tendrían interés en irse de su colonia, municipio, departamento o país. Como se recoge en la Tabla 11, un $61.8 \%$ de las personas encuestadas manifestó su interés en irse de la comunidad, el porcentaje más alto si se compara con los obtenidos cuando la pregunta se refiere a marcharse del municipio, departamento o país. Este porcentaje se incrementa a $76.8 \%$ en el caso de La Carpio y a un $68.2 \%$ en El Limón. 
Tabla 11

Distribuciones porcentuales del deseo de irse a vivir a otra comunidad, municipio, departamento o país según comunidad de residencia

\begin{tabular}{lccccccccc}
\hline & \multicolumn{10}{c}{ Deseo } \\
\cline { 2 - 10 } Comunidad & \multicolumn{3}{c}{$\begin{array}{c}\text { Irse a vivir a otra } \\
\text { comunidad }\end{array}$} & \multicolumn{1}{c}{ Irse a vivir a otro municipio } & Irse a vivir a otro país \\
& Sí & No & NS/NR & Sí & No & NS/NR & Sí & No & NS/NR \\
El Limón & 68 & 30 & 2 & 36 & 63 & 1 & 49 & 50 & 1 \\
Nueva Capital & 56 & 43 & 1 & 34 & 64 & 2 & 61 & 38 & 1 \\
Popotlán & 57 & 42 & 1 & 48 & 51 & 1 & 76 & 23 & 1 \\
Jorge Dimitrov & 51 & 46 & 3 & 28 & 70 & 2 & 47 & 51 & 2 \\
La Carpio & 77 & 19 & 4 & 66 & 25 & 9 & 50 & 47 & 3 \\
\hline
\end{tabular}

Fuente: Demandas ciudadanas de jóvenes residentes en barriadas populares en Centroamérica. Un estudio exploratorio regional, 2017.

Los datos obtenidos en La Carpio probablemente son resultado, al menos en parte, del estigma que se tiene de la comunidad en el resto del país (Sandoval et al., 2010). Incluso en Costa Rica se acuñó la expresión "Parecés de La Carpio" para referirse a actitudes o formas de conducirse que se consideran inapropiadas de acuerdo con el gusto que se podría llamar hegemónico.

En el caso del municipio, el porcentaje disminuye a $54.6 \%$. La Carpio, de nuevo, es la comunidad en donde se registra una mayor intención de salir (66.2 \%), seguida de Popotlán (48 \%). Las mujeres manifiestan mayor interés en irse respecto a los hombres (52.6\% y $47.6 \%$, respectivamente). Los resultados referidos a dejar el departamento o la provincia son semejantes, pues un 53.4 \% se iría. De nuevo, las mujeres superan a los hombres (53.4\% y $46.6 \%)$.

En lo que respecta a irse del país, el porcentaje de las personas que se irían es de un $57 \%$, solo superado por irse de la colonia o comunidad. Un $76.3 \%$ y un $60.6 \%$ de las personas encuestadas en Popotlán y Nueva Capital se iría. Si bien los riesgos de cruzar México son enormes, pues, a excepción de las personas costarricenses, las personas centroamericanas requieren visa, lo siguen intentando.

Entre quienes desearían irse del país, un $45.5 \%$ son mujeres y un $54.5 \%$ son hombres. Es decir, es el único caso en que las mujeres no son el grupo mayoritario que desearía irse. Ahora bien, si se analiza esta distribución de hombres y mujeres en perspectiva histórica, $y$ aunque no se disponga de series de datos para la región, se advertirá que el porcentaje de mujeres que viajan solas o con sus hijos e hijas está aumentando.

Ahora bien, una de las frecuentes interrogantes consiste en preguntarse qué factores obligan a dejar el país, a pesar incluso de los peligros de cruzar México y de las dificultades para cruzar la frontera y establecerse en los Estados Unidos. Al respecto, la prueba de hipótesis chi cuadrado de Pearson analizó la asociación estadística entre percepción de la distribución de la riqueza, violencia y confianza en las instituciones (en particular en la policía nacional), los principales temas que se han discutido en este artículo y la intención de irse del país.

La prueba de hipótesis reporta los siguientes valores: 0.005 para la variable de distribución de la riqueza, 0.011 para la 
variable de violencia y 0.027 para la variable de confianza en la policía nacional. Los tres valores son menores a 0.050 ; por lo tanto, se puede rechazar la hipótesis nula de que no existe asociación entre estas variables y el deseo de irse del país. Es decir, se cuenta con suficiente evidencia para afirmar que las variables de percepción de la distribución de la riqueza, percepción de violencia y confianza en la policía inciden en la intención de irse del país.

\section{Discusión y conclusiones}

Podría decirse que de este estudio emergen cuatro conclusiones principales. Una primera es más de tipo teórico y metodológico. Excepto en el caso de la colonia Jorge Dimitrov, en Nicaragua, las personas que facilitaron contactos en las colonias no laboran en universidades, desde donde no siempre son frecuentes los vínculos con quienes residen en colonias o comunidades populares. Sin estos vínculos, este proyecto no hubiera sido posible. Por ello, es muy importante tener muy presente que el trabajo comunitario, a menudo en sintonía con la educación popular y la investigación acción participativa, no está separado de la investigación si se quiere más académica.

Una segunda conclusión es que la ausencia de empleo y oportunidades de estudio están a la base de la exclusión de miles de jóvenes en Centroamérica. Porcentajes tan altos de desempleo en las colonias estudiadas tienen repercusiones de largo plazo en la vida de las personas. El empleo es una de las formas de distribución primaria del excedente (Pérez Sáinz, 2012) y carecer de este implica la imposibilidad de acceder a un mecanismo indispensable para la reproducción de la vida, lo cual se vuelve más dramático cuando se trata de personas jóvenes. No es difícil comprender por qué en comunidades con porcentajes tan altos de desempleo existen tantas manifestaciones de conflictividad social. Cualquier estrategia de largo plazo para procurar imaginar mejores condiciones de vida tiene que reconocer que el empleo es un factor de primer orden.

Iniciativas serias que pretendan asegurar la calidad de vida, en vísperas del Bicentenario de la Independencia, requieren reconocer que los desgarramientos sociales en Centroamérica son estructurales. Con frecuencia, los indicadores nacionales ofrecen cifras agregadas, por ejemplo, de empleo, las cuales no dan cuenta de las enormes disparidades entre regiones y sectores sociales, y al contabilizar el llamado empleo "informal" tienden a subestimar el desempleo.

Los hallazgos de esta investigación son relevantes, pues ni los medios de comunicación, ni los partidos políticos y menos los Gobiernos suelen tematizar la desigualdad como un rasgo de las sociedades centroamericanas. Mientras los discursos públicos suelen colocar la violencia criminal como el tema más reiterado, lo cual se evidencia cuando se pregunta cuál es el principal problema del país, las personas incluso muestran mayor coincidencia en la desigualdad en la distribución de la riqueza (Saraví, 2015).

El reconocimiento de la desigualdad no parece ser inducido por relatos o narrativas públicas sobre esta, sino más bien por la experiencia cotidiana de las personas encuestadas, desde la cual contrastan sus condiciones de vida con las de otras personas y grupos sociales. En este punto se abre un reto de primera importancia en el sentido de convertir esta "estructura del sentir" (Williams, 1980) en narrativas y relatos que permitan reconocer que lo que se vive a nivel personal y comunitario guarda relación con factores, si se quiere, más estructurales, como la carencia de trabajo remunerado u oportunidades de estudio, como ya se anotó.

Es preciso agregar que la indagación sobre la imagen de los otros y la autorepresentación abre muchas posibilidades interpretativas, por ejemplo, en términos de cuáles son las referencias para configurar la imagen de los otros acerca de la propia comunidad. Aunque la encuesta de la cual surge este artículo no 
permite profundizar en estas preguntas, sí se puede concluir que existen tensiones, derivadas de relaciones de poder desiguales, entre los discursos, para decirlo así del exogrupo, usualmente despectivos, y los del endogrupo, los cuales no encuentran fácil un proceso de identificación si se quiere afirmativa. Esta tensión no solo se expresa en términos narrativos o discursivos, sino que también toma forma en términos subjetivos y de actuación individual y colectiva.

Si se cotejan los indicadores demográficos y materiales con las promesas políticas del último ciclo electoral centroamericano que inició en Honduras en 2017 y finalizó en Guatemala en agosto de 2019, no cabe duda de que la democracia electoral se queda muy corta frente a la exclusión y las demandas de las nuevas generaciones entrevistadas en este estudio. Los hallazgos empíricos de este estudio apuntan a que la violencia, una suerte de implosión de las sociedades, y la migración forzada que obliga a salir pero que no encuentra modo de llegar a su destino, son especies de "salidas" a las crisis estructurales de las sociedades centroamericanas.

En 2017, en una sentencia sin precedentes, la Corte de lo Constitucional de $\mathrm{El}$ Salvador dio razón a las familias que interpusieron un recurso de amparo aduciendo que han sufrido desplazamiento forzado. La sentencia ordenó al Estado salvadoreño a crear condiciones para garantizar derechos fundamentales, lo cual es muy relevante, pues traduce, por la vía constitucional, el derecho a no tener que migrar al derecho positivo. Aunque la sentencia no garantiza a priori el cumplimiento de su contenido, sí establece un referente normativo para la exigibilidad de los derechos (Sala de lo Constitucional, 2017). En otras palabras, la evidencia estadística y la resolución de la Sala de lo Constitucional de El Salvador, ejemplos de tradiciones analíticas $e$ interpretativas, respectivamente, coinciden en reconocer los factores que están a la base de la migración forzada.

Aunado a lo anterior, la participación en iglesias neopentecostales caracterizan y estructuran la vida en las comunidades (Pérez Sáinz, 2019). Esta valoración más positiva de la confianza en las iglesias podría derivarse de su presencia comunitaria, pues, con frecuencia, las personas asisten a las actividades de estas iglesias no necesariamente atraídas por sus posturas teológicas, sino más bien por los servicios que prestan $\mathrm{y}$, no menos importante, por las sociabilidades que se despliegan en torno a sus actividades. Son, además, las instituciones que ofrecen una narrativa de futuro en un contexto en donde las limitaciones tienden a provocar una suerte de ahogo en medio de las presiones y las urgencias cotidianas.

No es de extrañar, entonces, que incluso en Costa Rica, en las elecciones celebradas en el año 2018, se haya consolidado la presencia de 14 (24\%) diputados y diputadas por parte del Partido Restauración Nacional, un partido abiertamente religioso. Tampoco sorprenden los resultados obtenidos en El Limón, si se toma en cuenta que el auge neopentecostal en Guatemala pronto superará a la Iglesia católica (Cantón, 1998).

¿Cuánto de estos desgarramientos podrían o no traducirse en acciones colectivas? Esta no es una pregunta de fácil respuesta. A dos años de las protestas ciudadanas en Nicaragua o de los intentos de sembrar una nueva "semilla" en la política de Guatemala, los escenarios de consolidación de propuestas colectivas no han sido ni serán tareas de corto plazo.

Una tercera consideración se refiere a las manifestaciones de ausencia de institucionalidad en las colonias. La violencia criminal y la ausencia de infraestructura y servicios públicos son los ejemplos más evidentes. Frente a este panorama, los retos son inmensos e incluyen la posibilidad de garantizar la libertad de movimiento y el derecho a permanecer en el lugar de residencia. Ello a su vez supone consolidar oportunidades de empleo y estudio, $e$ inversión en infraestructura y servicios, para lo cual se requiere inversión pública y privada, y ninguna de las dos parece estar disponible. 
Un cuarto conjunto de consideraciones se refiere a la cultura política que surge en estos contextos de exclusión. La ausencia de institucionalidad conduce, por una parte, a un debilitamiento de la legitimidad de la democracia, como documenta en respuestas a varias preguntas. Este debilitamiento crea condiciones para que opciones autoritarias, a menudo en conjunción con el neoconservadurismo religioso, articulen demandas casi por siempre no escuchadas.

Los resultados de la investigación son particularmente relevantes, pues evidencian una limitación para la agencia individual y colectiva al asumir la existencia de un destino predeterminado que conduciría hacia la resignación, pues el curso de la vida trascendería a las personas. Ello es más relevante cuando se trata de personas jóvenes en condiciones de pobreza. Ignacio Martín Baró (1989, p. 160) sugiere que se trata de una "inhibición aprendida", es decir, la resignación resulta de procesos sociohistóricos y subjetivos que han prevenido las posibilidades de demandar y de construir autonomías. La identificación con la autoridad, tanto en referencia al destino o a los padres, por otra parte, es un terreno abonado para el discurso religioso neoconservador, el cual se apropia de estos referentes para legitimar su discurso y no se diga sus intereses.

Pese a lo anterior, el reconocimiento de las desigualdades podría ser un punto de articulación de esfuerzos e iniciativas políticas progresistas. Se trataría de concebir la política como una pedagogía en la cual se tejan esfuerzos grupales y narrativos que permitan nombrar colectivamente las desigualdades tanto social como subjetivamente. Este artículo intenta aportar andamios para esta construcción.

\section{Referencias bibliográficas}

S. a. (1987). Procedimiento para establecer la paz firme y duradera en Centroamérica (Acuerdo de Esquipulas II, 7 de agosto de 1987). Relaciones
Internacionales, 19(1), 97-102. https:// www.revistas.una.ac.cr/index.php/ri/article/ view/7311

Adorno, T. W., Frenkel-Brunswick E., Levinson, D. J. y Sanford, R. N. (1959). The Authoritarian Personality. Harper.

Amarante, V., Galbán M. y Mancero, X. (2016). Desigualdad en América Latina: una medición global. Revista CEPAL, 118, 27-47. https://repositorio.cepal.org/bitstream/ handle/11362/40024/1/RVE118_Amarante.pdf

Asmann, P. (4 de mayo de 2017). Proyecto de ley antipandillas en Guatemala, ¿otra política fallida de 'mano dura'? InSight Crime. https://es.insightcrime.org/noticias/ noticias-del-dia/proyecto-ley-antipandillas-guatemala-otra-fallida-politica-mano-dura/

Batthyány, K., Sol Cabrera, M., Dede, G. Macadar, D. y Pardo, I. (2005). Género y pobreza: un caso de desigualdades entrelazadas. En Informe Social Watch 2005: Rugidos y susurros. http://www.socialwatch.org/sites/ default/files/pdf/es/generopobreza2005_esp.pdf

Bourdieu, P. (1990). Sociología y cultura. Editorial Grijalbo.

Duarte, K. (2000). ¿Juventud o juventudes? Acerca de cómo mirar y remirar a las juventudes de nuestro continente. Última década, 8(13), 59-77. https://scielo. conicyt.cl/scielo.php?script =sci_arttext\&pid=S0718-22362000000200004

Fraser, N. (2013). The Fortunes of Feminism. Verso.

Gutiérrez, D. (27 de febrero de 2016). El Salvador: Por qué la guerra social es una guerra. La Haine. https://www.lahaine.org/ mm_ss_mundo.php/el-salvador-por-que-la

Hall, S. (2010). Sin garantías. Trayectorias $y$ problemáticas en Estudios Culturales. En E. Restrepo et al. Envión Editores.

Hansen-Nord, S. N., Kjaerulf, F., Almendarez, J., Morales Rodas, V. \& Castro, J. (2016). Reducing violence in poor urban areas of Honduras by building community 
resilience through community-based interventions. International Journal of Public Health, 61(8), 935-943. https://econpapers.repec.org/ article/sprijphth/v_3a61_3ay_3a2016_3ai_3a8 _3ad_3a10.1007_5fs00038-016-0854-4.h̄tm

Hernández, R., Fernández, C. y Baptista, P. (2014). Metodología de la investigación. McGraw-Hill.

Hill Collins, P. y Bilge S. (2016). Intersectionality. Polity.

Lechner, N. (1990). Los patios interiores de la democracia. Subjetividad y política. FCE.

Margulis, M. (Ed.). (1996). La juventud es más que una palabra. Ensayos sobre cultura y juventud. Biblos.

Martín Baró, I. (1989). Sistema, grupo y poder. UCA editores.

Pérez Sáinz, J. P. (2012). Exclusión social. Una propuesta crítica para abordar las carencias sociales en América Latina. En Sociedades fracturadas. La exclusión social en Centroamérica. FLACSO.

Pérez Sáinz, J. P. (2019). La rebelión de los que nadie quiere ver. Respuestas para sobrevivir a las desigualdades extremas en América Latina. Siglo XXI FLACSO Costa Rica.

Programa Estado de la Nación en Desarroll o Humano Sostenible. (2016). Cuarto Informe Estado de la Región. PEN.
Sala de lo Constitucional. (2017). Amparo 411-2017, El Salvador. http://www.csj. gob.sv/Comunicaciones/2018/07 JULIO/ COMUNICADOS/Amp. \%20411-20̄17\%20 Sentencia\%20desplazamiento_7MZT.pdf

Sandoval, C. et al. (2010). Un país fragmentado. La Carpio: Cultura, comunidad y política. EUCR.

Sandoval, C. (2015). No más muros. Exclusión y migración forzada en Centroamérica. EUCR. https://cpalsocial.org// documentos/190.pdf

Saraví, G. (2015) Juventudes fragmentadas. Socialización, clase y cultura en la construcción de la desigualdad. FLACSO CIESAS.

Úriz, M. J. (1993). Personalidad, socialización y comunicación. Libertarias.

Wallerstein, I. (Coord.) (1996). Abrir las ciencias sociales. Siglo XXI.

Williams, R. (1988). Marxismo y literatura. Península.

Wright Mills, Ch. (1987). La imaginación sociológica. FCE.

Yuval-Davis, N. (2010). The Politics of Belonging. Intersectional Contestations. Sage. 